\title{
Evaluasi Sistem Distribusi Air Bersih Zona Rumah Pompa Krembangan Kota Surabaya
}

\section{Farhan Putra Budiman ${ }^{1 *}$, Riyanto Haribowo ${ }^{1}$, M Janu Ismoyo $^{1}$}

${ }^{1}$ Jurusan Teknik Pengairan, Fakultas Teknik, Universitas Brawijaya

Jl. MT. Haryono No. 167, Malang, 65145, Indonesia

*Korespondensi Email: fputrabudiman@gmail.com

\begin{abstract}
The clean water distribution system for the Krembangan Pump House has a fairly large drainage area. This study aims to determine the existing conditions and conditions of network development in terms of water availability and demand, hydraulic conditions and water quality, and conditions of fire extinguishing wells in the network with a simulation of the WaterCad v8i. From the analysis result, the existing condition's network condition shows a deficit between water demand and availability of $149 \mathrm{l} / \mathrm{s}$. Hydraulic conditions during peak hours of use, parameters $100 \%$ pressure, speed, and headloss gradient $74.1 \%$ do not become eligible. Residual chlorine does not qualify. The condition of the network development was improved by adding pipes to be parallel and adding one pump. The development conditions were simulated with three different conditions: reducing the water demand standard, rotating the water flow, and reducing the service area. The simulation results, the average pressure is between $0.8-10 \mathrm{~atm}$. velocity $0.3-6 \mathrm{~m} / \mathrm{s}$, and a headloss gradient of $0-15 \mathrm{~m} / \mathrm{km}$. The sumur pemadam kebakaran (SPMK) simulation showed that the water did not fill the average well again at $09.00-16.00$.
\end{abstract}

Keywords: PDAM, RP Krembangan, Surabaya City, WaterCad v8i

\begin{abstract}
Abstrak: Sistem distribusi air bersih zona Rumah Pompa Krembangan memiliki daerah pengaliran yang cukup luas. Penelitian ini bertujuan untuk mengetahui kondisi eksisting dan kondisi pengembangan jaringan dari sisi ketersedian serta kebutuhan air, kondisi hidraulik serta kualitas air, dan kondisi sumur pemadam kebakaran pada jaringan dengan simulasi program WaterCadv8i. Kondisi jaringan pada kondisi eksisting terdapat defisit antara kebutuhan dan ketersediaan air sebesar 149 1/s. Kondisi hidraulik saat jam pemakaian puncak, parameter tekanan $100 \%$, kecepatan, dan headloss gradient $74,1 \%$ tidak memenuhi syarat. Kualitas air masih belum terpenuhi syarat sisa klorin pada jaringan. Kondisi pengembangan jaringan diperbaiki dengan merubah 50 pipa menjadi paralel dan menambah satu buah pompa. Kondisi pengembangan dilakukan simulasi dengan tiga kondisi yaitu mengurangi standar kebutuhan air, melakukan penggiliran pengaliran air, dan mengurangi daerah pelayanan. Hasil simulasi, rata-rata tekanan berada diantara 0,8-10 atm. kecepatan 0,3-6 m/s, dan headloss gradient 0-15 m/km. SPMK, dilakukan simulasi, hasilnya menunjukan rata-rata sumur tidak terisi penuh kembali pada pukul 09.00 - 16.00.
\end{abstract}

Kata kunci: Kota Surabaya, PDAM, RP Krembangan, WaterCad $v 8 i$ 


\section{Pendahuluan}

Kota Surabaya merupakan kota kedua terbesar di Indonesia setelah Jakarta. Kota Surabaya juga merupakan Ibu Kota Provinsi Jawa Timur sekaligus Kota Metropolitan terbesar di Provinsi tersebut. Dengan kondisi tersebut tentunya Kota Surabaya banyak dikunjungi bahkan dijadikan tempat menetap. Hal ini tentunya memiliki dampak terhadap jumlah penduduk Kota Surabaya yang terus meningkat setiap tahunnya. Pada tahun 2010 jumlah penduduk Kota Surabaya sebanyak 2.862.406 Jiwa sedangkan pada tahun 2019 sebanyak 2.941.981 Jiwa. Memiliki tingkat pertumbuhan penduduk yang tinggi tentunya Kota Surabaya juga memiliki kebutuhan air bersih yang tinggi

Zona Rumah Pompa Krembangan sendiri merupakan daerah yang padat penduduk. Pada zona ini, jaringan PDAM seringkali dikeluhkan dengan kecilnya debit yang sampai di sambungan rumah, sehingga seringkali terjadinya rotasi air yang keluar. Agar air yang ada lebih efektif, sebagian pelanggan memilih menampung terlebih dahulu air dari PDAM tersebut. Air yang keluar tidak secara terus menerus sehingga menampung terlebih dahulu merupakan suatu solusi. Padatnya penduduk pada Zona Rumah Pompa Krembangan akan menimbulkan resiko bencana kebakaran yang lebih tinggi.

Perlu dilakukan penelitian lebih lanjut terhadap sistem distribusi air bersih zona Rumah Pompa Krembangan Kota Surabaya. Penelitian lebih lajut tersebut bermaksud untuk menghitung besarnya ketersediaan air dan kebutuhan air pada kondisi eksisting tahun 2019 dan kondisi pengembangan tahun 2039, mengsimulasikan kondisi hidraulik serta kualitas air berupa sisa klorin pada kondisi eksisting (2019) dan kondisi pengembangan (2039), dan melakukan simulasi kondisi jaringan dengan keberadaan sumur pemadam kebakaran dengan kondisi ideal. Analisa yang digunakan dalam penelitian ini dilakukan menggunakan simulasi program WaterCad $v 8 i$. Penelitian dilakukan secara sitematis dengan melakukan pengumpulan data, analisis jumlah penduduk serta pelanggan PDAM, evaluasi sistem hidraulik menggunakan program WaterCad v8i [1]. Adapun manfaat yang diharapkan dari penelitian ini adalah mengetahui kebutuhan air serta ketersediaan air, mengetahui kondisi hidraulik serta kualitas air, dan mengetahui kondisi sumur pemadam kebakaran pada jaringan dalam kondisi eksisting tahun 2019 sehingga dapat diberikan solusi agar pada kondisi pengembangan tahun 2039 jaringan bisa bekerja secara optimal.

\section{Bahan dan Metode}

\subsection{Bahan}

\section{A. Wilayah Studi}

Penelitian ini dilakukan pada sistem distribusi air bersih pada Zona Rumah Pompa Krembangan PDAM Surya Sembada, Kota Surabaya. Air yang di tampung pada Rumah Pompa Krembangan berasal dari tandon Rumah Pompa Besar Putat Gede. Sedangkan air yang ada pada tandon Rumah Pompa Besar Putat Gede berasal dari Instalansi Karang Pilang II dan sebagian dari Intalasi Ngagel yang mengolah air hingga bersih dari Kali Surabaya. Sistem distribusi air bersih Zona Rumah Pompa Krembangan memiliki jaringan pipa di sebagian zona 3 PDAM Surabaya yang meliputi Kecamatan Pabean Cantian, Kecamatan Semampir, dan Kecamatan Kenjeran. Zona Rumah Pompa Krembangan melayani air bersih untuk subzona 309, 313, 314, dan 316 dengan jumlah 30832 pelanggan dan 7 titik sumur pemadam kebakaran. 


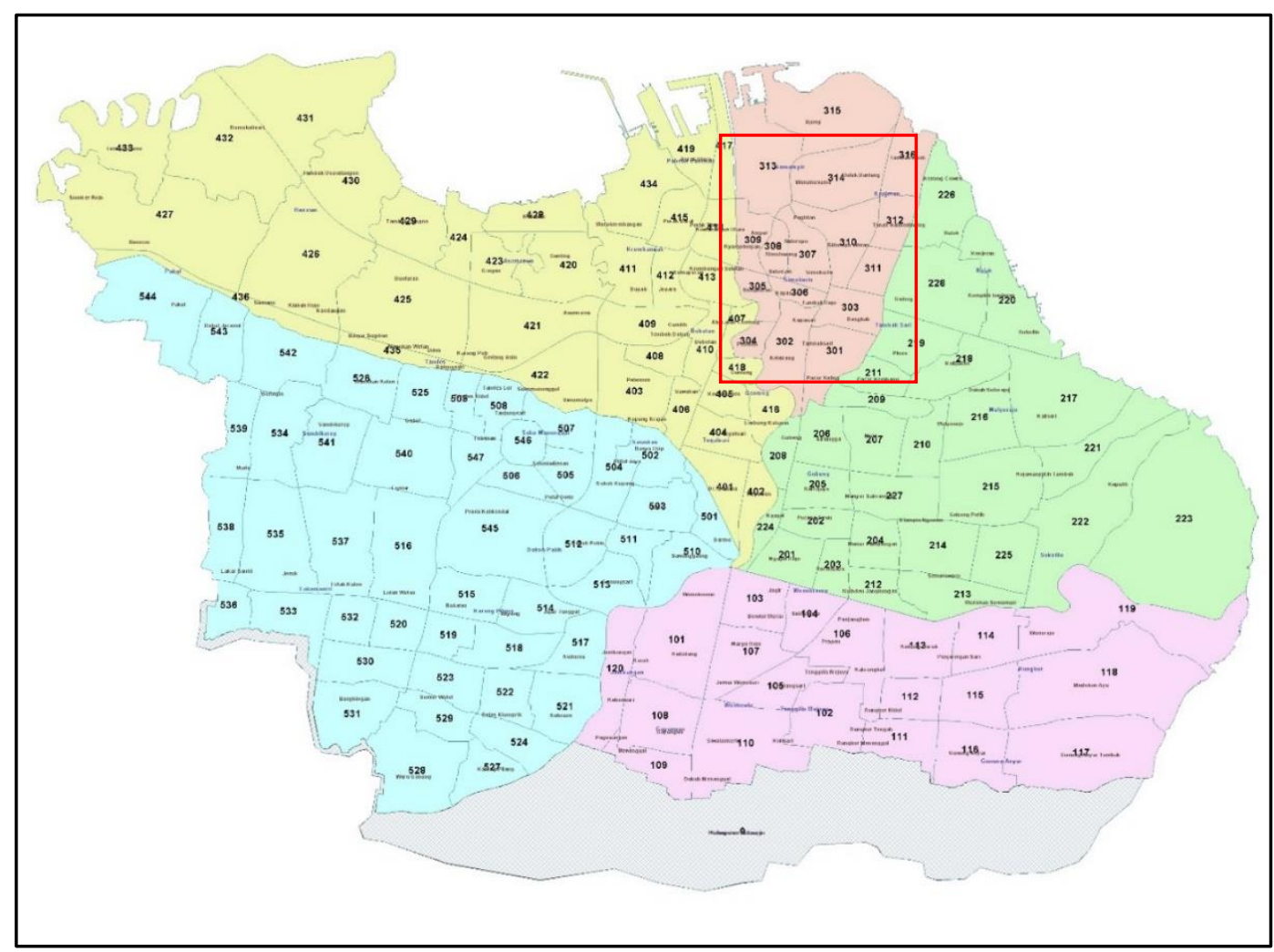

Gambar 1: Pembagian Zona PDAM Kota Surabaya

B. Data penelitian yang dibutuhkan

- Data Jumlah Penduduk Kecamatan Semampir, Kenjeran, dan Pabean Cantian yang didapat dari BPS Kota Surabaya.

- Data Jumlah Pelanggan PDAM Surya Sembada Kota Surabaya khususnya Subzona 309, 313, 314, dan 316 yang diperoleh dari PDAM Surya Sembada Kota Surabaya.

- Data debit pada sumber air dan data penginjeksian klorin yang diperloeh dari PDAM Surya Sembada Kota Surabaya.

- Data dan Peta Jaringan PDAM Surya Sembada yang diperoleh dari PDAM Surya Sembada Kota Surabaya.

- Data dan Peta Sebaran titik sumur pemadam kebakaran (SPMK) yang didapat dari BAPEKKO dan Dinas Pemadam Kebakaran Kota Surabaya.

\subsection{Metode}

Simulasi yang dilakukan pada penelitian ini menggunakan program WaterCad v8i. WaterCAD $v 8 i$ merupakan program yang dihasilkan dari perusahaan Bentley. Dalam panduan penggunaannya, WaterCAD $v 8 i$ dapat menganalisis 250 pipa sesuai dengan spesifikasi yang sudah ditentukan. WaterCAD $v 8 i$ dibuat agar memudahkan dalam hal menganalisis dan mengoptimalisasi suatu jaringan perpipaan [2]. WaterCad $v 8 i$ adalah program pemodelan hidraulik yang terdiri dari berbagai fungsi termasuk tahapan pada profil dan memiliki grafis yang fleksibel. Memiliki fitur kemampuan simulasi jangka panjang dan memiliki integrase dengan program AutoCad serta GIS [3]. Simulasi dilakukan setelah sebelumnya didapat perhitungan kebutuhan air bersih berdasarkan data pelanggan. 


\section{Hasil dan Pembahasan}

\subsection{Kebutuhan Air Bersih}

Besarnya pemakaian oleh masyarakat dipengaruhi oleh banyak faktor, dengan demikian, dalam perencanaan suatu sistem penyediaan air, kemungkinan penggunaan air dan variasinya haruslah diperhitungkan secermat mungkin.

Proyeksi penduduk merupakan perhitungan ilmiah yang didasarkan pada asumsi dari komponenkomponen laju pertumbuhan penduduk, yaitu kelahiran, kematian, dan perpindahan penduduk (migrasi). Ketiga komponen tersebutakan menentukan jumlah dan struktur umur penduduk di masa depan [4].

Berikut perhitungan proyeksi penduduk dengan menggunakan metode aritmatik pada subzona 309:

$$
\begin{aligned}
\mathrm{Pt} & =\mathrm{Po}(1+\mathrm{rt}) \\
& =3461(1+(0,0249 \times 10)) \\
& =4368 \text { Pelanggan }
\end{aligned}
$$

Tabel 1: Hasil Proyeksi Penduduk Metode Aritmatik pada Subzona 309

\begin{tabular}{cccc}
\hline Tahun & $\begin{array}{c}\text { Jumlah Pelanggan } \\
\text { Sub Zona 309 }\end{array}$ & Tahun & $\begin{array}{c}\text { Jumlah Pelanggan } \\
\text { Sub Zona 309 }\end{array}$ \\
\hline 2019 & 3461 & 2030 & 4458 \\
2020 & 3552 & 2031 & 4549 \\
2021 & 3642 & 2032 & 4640 \\
2022 & 3733 & 2033 & 4730 \\
2023 & 3824 & 2034 & 4821 \\
2024 & 3914 & 2035 & 4912 \\
2025 & 4005 & 2036 & 5002 \\
2026 & 4096 & 2037 & 5093 \\
2027 & 4186 & 2038 & 5184 \\
2028 & 4277 & 2039 & 5274 \\
2029 & 4368 & & \\
\hline
\end{tabular}

Setelah dilakukan perhitungan proyeksi penduduk maka dilakukan uji kesesuaian metode proyeksi. Pemilihan metode proyeksi pertumbuhan penduduk berdasarkan cara pengujian statistik yakni berdasarkan pada nilai koefisien korelasi yang menunjukan kuat atau tidaknya hubungan linier antar dua variabel, yakni terbesar mendekti +1 [5]. Dari pernyataan tersebut maka metode proyeksi yang perhitungan koefisien korelasi nya mendekati +1 adalah metode aritmatik.

Tabel 2: Hasil Perhitungan Koefisien Korelasi

\begin{tabular}{cccc}
\hline & \multicolumn{3}{c}{ Metode Proyeksi } \\
\cline { 2 - 4 } & Aritmatik & Geometrik & Eksponensial \\
\hline $\mathrm{X}$ & 2247958 & 2247958 & 2247958 \\
$\mathrm{Y}$ & 2253821 & 2224808 & 2224808 \\
$\mathrm{X} . \mathrm{Y}$ & 1014579962335 & 1016387581989 & 1001234370778 \\
$\mathrm{X} 2$ & 1011860489106 & 1011860489106 & 1011860489106 \\
$\mathrm{Y} 2$ & 1017319693011 & 1020961924239 & 990760680244 \\
$\mathrm{n}$ & 5 & 5 & 5 \\
$\mathrm{r}$ & 0,997247 & 0,996588 & 0,996594 \\
\hline
\end{tabular}


Tabel 3: Perhitungan Kebutuhan Air Bersih pada Zona RP Krembangan Tahun 2019 - 2039

\begin{tabular}{|c|c|c|c|c|c|c|c|}
\hline \multirow{2}{*}{ No } & \multirow{2}{*}{ Keterangan } & \multirow{2}{*}{ Satuan } & \multicolumn{5}{|c|}{ Tahun Proyeksi } \\
\hline & & & 2019 & 2024 & 2029 & 2034 & 2039 \\
\hline 1 & Jumlah Pelanggan & SR & 30832 & 34870 & 38908 & 42947 & 46985 \\
\hline 2 & Jumlah Jiwa/Sambungan Rumah & Jiwa & 5 & 5 & 5 & 5 & 5 \\
\hline 3 & Standar Kebutuhan Air & lt/org/hr & 150 & 150 & 150 & 150 & 150 \\
\hline \multirow[t]{2}{*}{4} & Kebutuhan Air Domestik & $\mathrm{lt} / \mathrm{hr}$ & 23124000 & 26152626 & 29181252 & 32209879 & 35238505 \\
\hline & & lt/dtk & 268 & 303 & 338 & 373 & 408 \\
\hline 5 & Kebutuhan Air Non Domestik & lt/dtk & 40 & 45 & 51 & 56 & 61 \\
\hline 6 & Total Kebutuhan Air & lt/dtk & 308 & 348 & 388 & 429 & 469 \\
\hline 7 & Kehilangan Air & lt/dtk & 62 & 70 & 78 & 86 & 94 \\
\hline 8 & Kebutuhan Air Bersih Rata-Rata & lt/dtk & 369 & 418 & 466 & 514 & 563 \\
\hline 9 & Kebutuhan Harian Maksimum & lt/dtk & 425 & 480 & 536 & 592 & 647 \\
\hline 10 & Kebutuhan Jam Puncak & lt/dtk & 576 & 652 & 727 & 803 & 878 \\
\hline
\end{tabular}

Kebutuhan air setiap tahunnya semakin meningkat beriringan dengan bertambahnya jumlah pelanggan. Dengan kondisi ketersediaan air sumber sebesar 220 liter/detik maka dipastikan air tidak mencukupi untuk mengaliri seluruh jaringan. Perlu dilakukan beberapa cara agar ketersediaan air dapat seimbang dengan kebutuhan air. Kebutuhan air yang digunakan pada simulasi adalah kebutuhan air bersih rata-rata yang dikalikan dengan load factor.

3.2 Kondisi Eksisting Jaringan (2019)

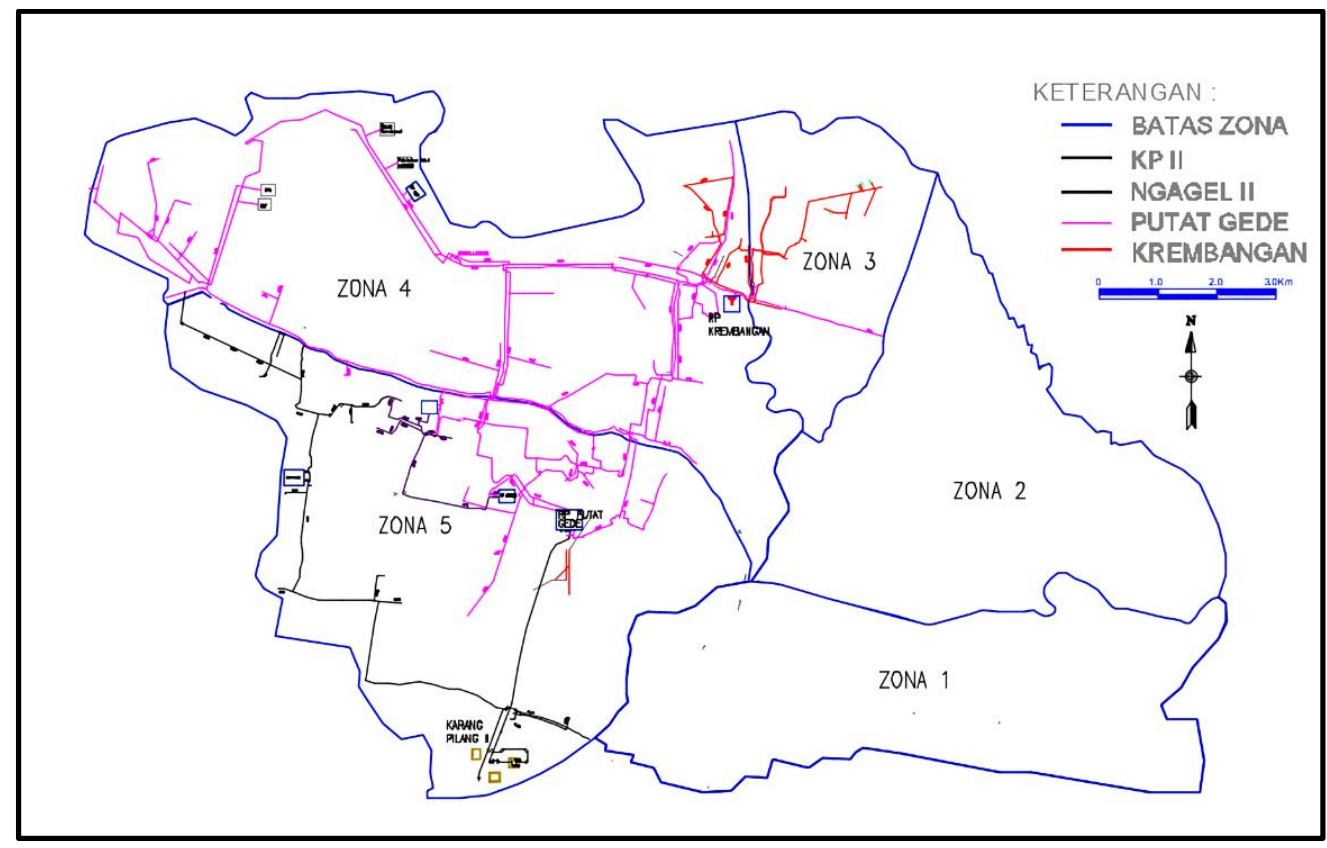

Gambar 2: Sistem Distribusi Air Bersih RP Krembangan

Air di dalam pipa selalu mengalir dari tempat yang memiliki tinggi energi lebih besar menuju tempat yang memiliki tinggi energi lebih kecil. Aliran tersebut memiliki tiga macam energi yang bekerja di dalamnya yaitu energi kinetik, energi tekanan, dan energi ketinggian [6].

Untuk mengetahui kondisi hidraulik berupa tekanan, kecepatan, dan headloss gradient pada sistem distribusi air bersih zona RP Krembangan pada kondisi eksisting maka dilakukan simulasi 
menggunakan program WaterCAd $v 8 i$. Selain itu dilakukan juga simulasi kualitas air. Kualitas air dinyatakan dengan beberapa parameter, yaitu parameter fisika, kimia, dan biologi [7]. Kualitas air yang dimaksud adalah proses desinfeksi. Desinfeksi merupakan proses menonaktifkan dan menghancurkan (membunuh) organisme yang mengganggu kesehatan maupun estetika. Pada jaringan RP Krembangan desinfeksi dilakukan berupa peninjeksian klorin untuk mengetahui sisa klorin yang sampai pada pelanggan.

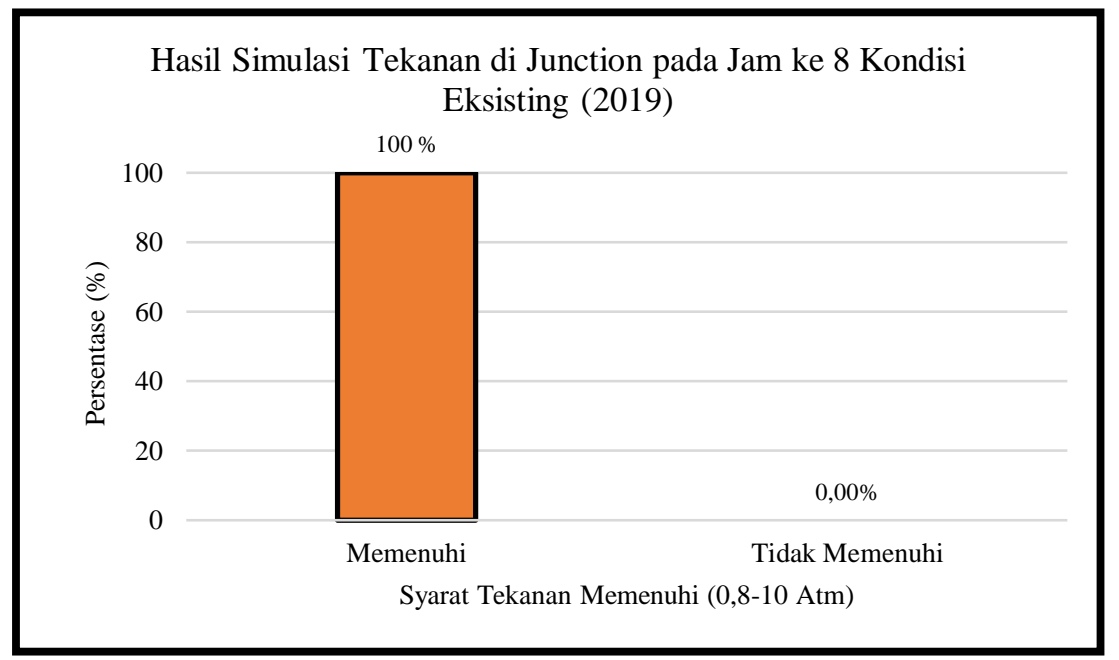

Gambar 3: Hasil Simulasi Tekanan pada Jam ke 08.00 Kondisi Eksisting (2019)

Gambar diatas menunjukan bahwa pada jam ke 08.00 seluruh junction tidak memenuhi nilai tekanan sebesar 0,8 sampai 10 atm. Semua nilai tekanan pada junction di jaringan ini tidak memenuhi syarat dikarenakan memiliki nilai dibawah 0,8 atm. Penambahan jumlah pemakaian air pada pukul 08.00 dapat mengakibatkan nilai tekanan turun. Nilai tekanan yang kecil juga dapat disebabkan karena headloss terlalu besar. Headloss terlalu besar dapat diminimalisir dengan menambah pipa secara paralel, memperbesar pipa, dan menambah pompa

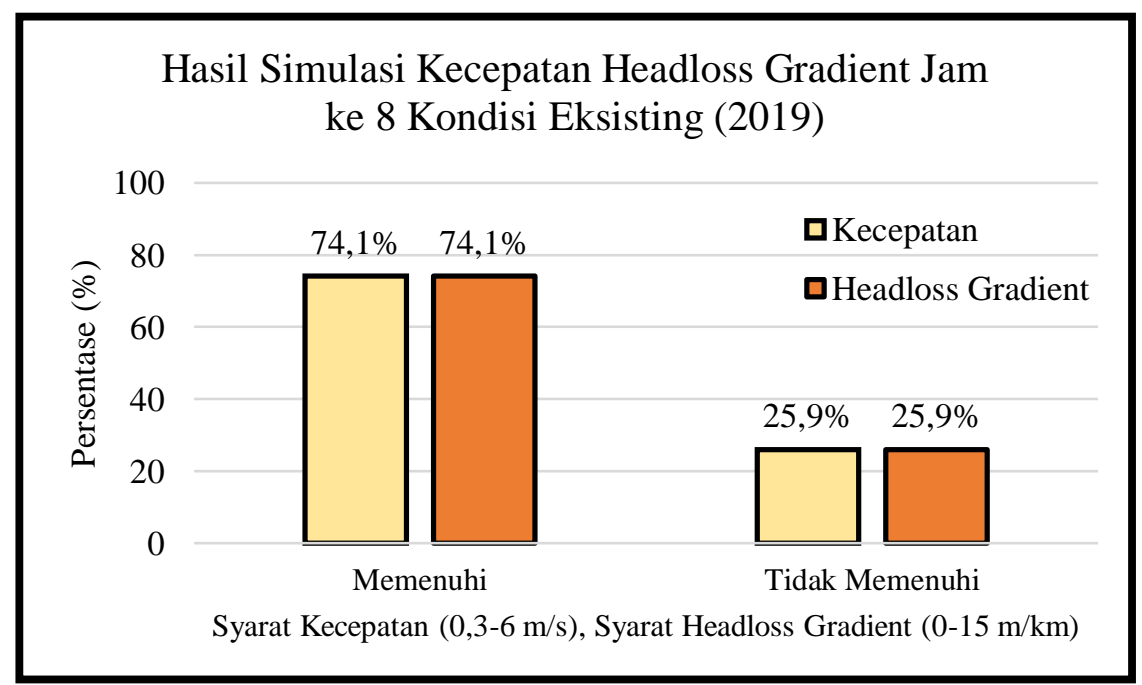

Gambar 4: Hasil Simulasi Kecepatan dan Headloss Gradient pada Jam ke 08.00 Kondisi Eksisting (2019)

Gambar diatas menjelaskan hasil simulasi kecepatan pada jam ke 08.00 kondisi eksisting dengan menggunakan aplikasi WaterCad V8i yang hasilnya 74,1 persen memenuhi syarat dan 25,9 persen tidak memenuhi syarat. Adapun syarat memenuhi tekanan adalah antara $0,3 \mathrm{~m} / \mathrm{s}-6 \mathrm{~m} / \mathrm{s}$.

Gambar diatas menunjukan hasil simulasi headloss gradient pada jam ke 08.00 kondisi eksisting menggunakan aplikasi WaterCad V8i yang hasilnya 74,10 persen memenuhi syarat headloss gradient 
sedangkan 25,90 persen tidak memenuhi syarat headloss gradient. Syarat headloss gradient sendiri hasil simulasi harus berada diantara $0-15 \mathrm{~m} / \mathrm{km}$. Perbedaan hasil kecepatan dan headloss gradient sendiri dipengaruhi oleh beberapa faktor yaitu kebutuhan air, diameter pipa, dan koefisien kekasaran pipa. Kebutuhan air yang tinggi akan membuat kecepatan pun tinggi sehingga headloss gradient pun tinggi. Pada dinding yang mendekati licin sempurna, masih pula terjadi kehilangan energi walaupun sangan kecil. Jika dinding licin sempurna, maka tidak ada kehilangan energi, yaitu saat diameter kekasaran nol [8].

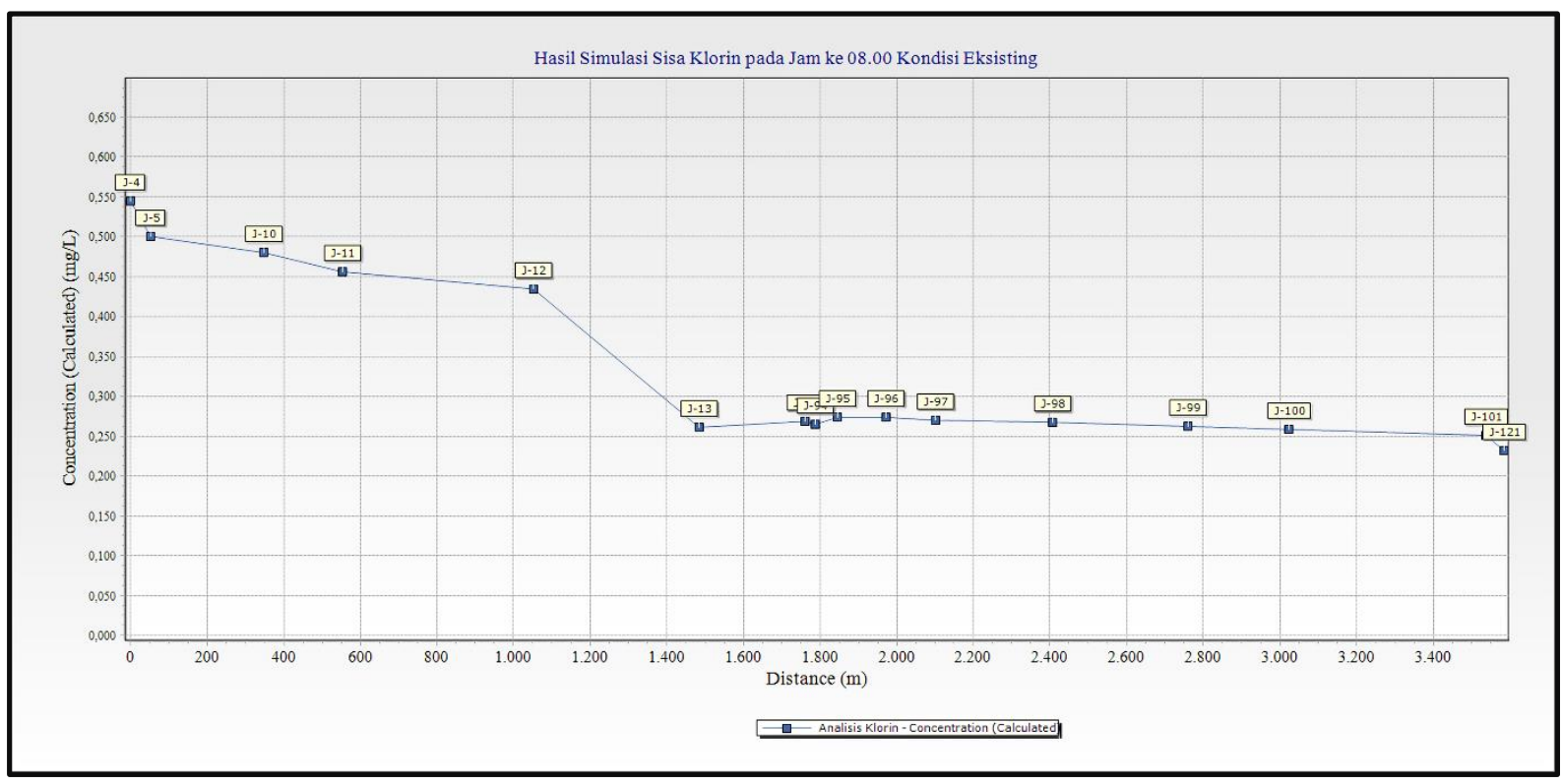

Gambar 5: Hasil Simulasi Sisa Klorin pada Jam ke 08.00 Kondisi Eksisting (2019)

Penggunaan gas klorin dalam jaringan SPAM menuntut kecermatan tinggi agar tidak mencelakakan manusia [9]. Pada umumnya, desinfeksi (Klorinasi) berjalan efektif setelah waktu kontak 30 menit dengan free available chlorine antara $0,2 \mathrm{mg} / 1$ hingga $0,5 \mathrm{mg} / 1$ atau combined available chlorine atantara $2 \mathrm{mg} / \mathrm{l}$ hingga $3 \mathrm{mg} / \mathrm{l}$ [10]. Gambar diatas merupakan hasil simulasi sisa klorin pada jam ke 08.00 kondisi eksisting menggunakan aplikasi WaterCad V8i. Grafik tersebut menggambarkan hubungan antara sisa klorin dengan jarak junction. Dari simulasi tersebut, semakin jauh jarak junction maka sisa klorin semakin sedikit. Pada junction 4 sisa klorin terdapat $0,55 \mathrm{mg} / \mathrm{l}$, dan pada junction terjauh terdapat $0,202 \mathrm{mg} / \mathrm{l}$. Sisa klorin pada sistem distribusi air bersih saat ini dirasa masih kurang karena sebagian daerah pengaliran masih belum memenuhi syarat sisa klorin, sehingga pada tahap pengembangan akan dilakukan penambahan penginjeksian pada Tandon Krembangan.

\subsection{Kondisi Pengembangan Jaringan (2039)}

Penyelenggaran pengembangan sistem penyedian air minum, proyeksi pertumbuhan harus memiliki rentang periode perencanaan 15 - 20 tahun dengan pengkajian ulang setiap 5 tahun [11]. Perencanaan pengembangan sistem distribusi air bersih ini dilakukan untuk 20 tahun kedepan tepatnya sampai tahun 2039. Perencanaan pengembangan ini dilakukan dengan memperbaiki sistem distribusi air bersih kondisi eksisting (2019). Perbaikan tersebut dengan mesemang pipa secara paralel sebanyak 54 buah pipa dan penambahan satu buah pompa. Solusi penggantian pipa dengan diameter yang lebih kecil hanya akan memperbesar headloss gradient, oleh sebab itu tidak dapat dilakukan [12].

Pada tahun 2039 dengan jumlah pelanggan yang terus meningkat setiap tahunnya, maka akan muncul masalah baru pada jaringan. Simulasi pada kondisi pengembangan akan menggunakan sumber air yang sama dengan kondisi eksisting. Pada perencanaan pengembangan diberikan tiga solusi untuk 
memecah masalah ketidak seimbangan antara kebutuhan dan ketersediaan, dalam hal ini kebutuhan lebih besar dari ketersediaan. Ketiga solusi tersebut diantaranya adalah:

a. Mengurangi jatah liter/orang/hari yang semula $150 \mathrm{lt} / \mathrm{org} / \mathrm{hari}$ menjadi $80 \mathrm{lt} / \mathrm{org} / \mathrm{hari}$.

b. Melakukan penggiliran pengaliran air dimana pengklusteran sesuai dengan subzona.

c. Melakukan pengurangan subzona yang dialiri oleh Rumah Pompa Krembangan.

Solusi A dengan mengurangi standar kebutuhan air menjadi 80 liter/orang/hari makan kebutuhan air bersih menjadi berkurang signifikan namun dengan keadaan Kota Surabaya yang merupakan kota Metropolitan menjadikan standar kebutuhan tersebut kurang. Solusi B melakukan pengggiliaran pengaliran air mengharuskan sambungan rumah untuk mempunyai tampungan agar ketika sedang mendapat penggiliran masih tersedia cadangan air. Penggiliran dilakukan dilakukan setiap dua jam sekali dimulai pukul 03.00 dan berakhir pukul 22.00 sehingga masing-masing kluster medapat giliran 16/24 jam. Solusi C pengurangan subzona 314 dikarenakan kebutuhan yang sangat besar sehingga subzone tersebut disarankan untuk dipindahkan sumbernya atau dilakukan pembagian beban oleh beberapa Rumah Pompa.

Tabel 4: Kebutuhan Air Bersih pada Kondisi Pengembangan (2039)

\begin{tabular}{ccccc}
\hline \multirow{2}{*}{ No } & \multirow{2}{*}{ Subzona } & \multicolumn{3}{c}{ Kebutuhan Air Rata-Rata(1/s) } \\
\cline { 3 - 5 } & & Solusi A & Solusi B & Solusi C \\
\hline 1 & 309 & 33,7 & 34,7 & 63,2 \\
2 & 313 & 40 & 41,3 & 75 \\
3 & 314 & 157 & 162,2 & 0 \\
4 & 316 & 69 & 70,9 & 129 \\
\hline \multicolumn{2}{c}{ Total } & 299,7 & 309,1 & 267,2 \\
\hline
\end{tabular}

Tiga solusi yang berbeda memiliki kebutuhan air bersih yang berbeda. Solusi B memiliki kebutuhan air bersih yang paling besar dengan 309,1 liter/detik dan solusi C memiliki kebutuhan air bersih paling kecil dengan 267,2 liter/detik. Untuk mengetahui solusi mana yang paling tepat maka dilakukan simulasi WaterCad v8i untuk mengetahui nilai tekanan, kecepatan, headloss gradient, dan kualitas air.

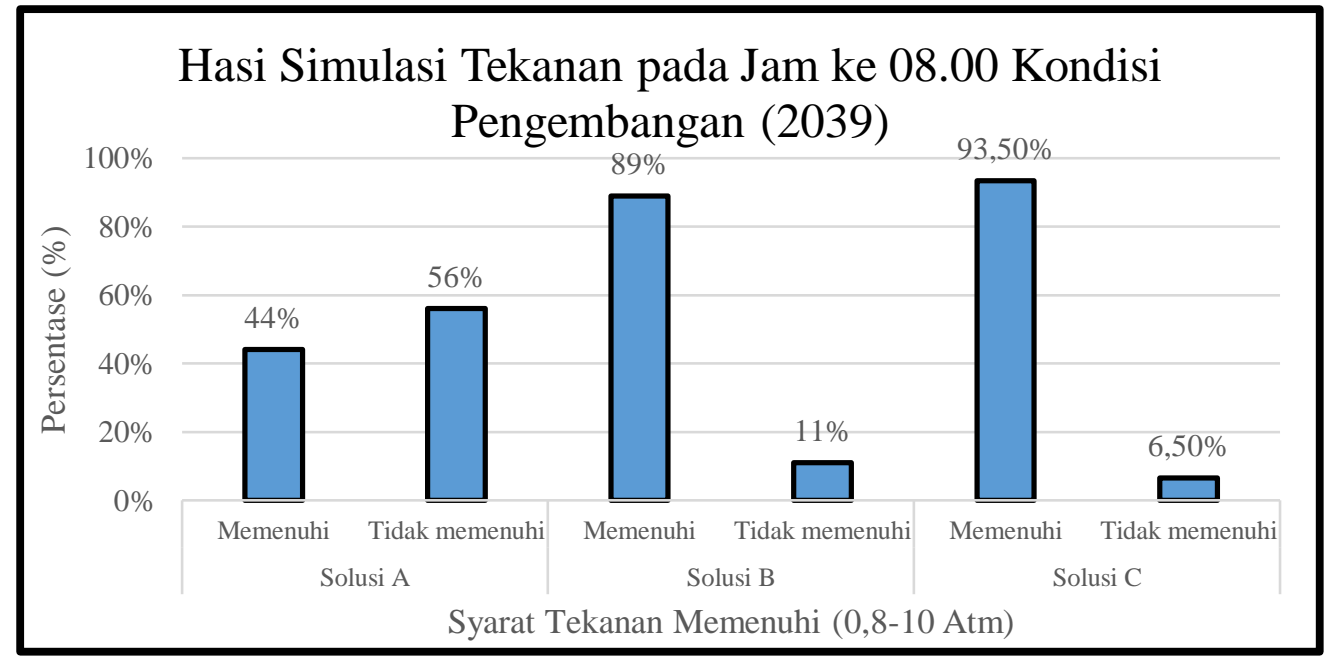

Gambar 6: Hasil Simulasi Tekanan pada Jam ke 08.00 Kondisi Pengembangan (2039)

Gambar diatas menunjukan bahwa masing-masing solusi memiliki hasil simulasi yang berbeda. Simulasi ini dilakukan pada jam 08.00 dimana jam tersebut merupakan jam puncak pemakaian air bersih dengan faktor pengali sebesar 1,56. Pada simulasi tekanan ini, solusi b paling memenuhi syarat dengan $93,5 \%$ junction pada jaringan yang memenurhi syarat tekanan $(0,8-10 \mathrm{~atm})$. Solusi A sebanyak $56 \%$ junction yang ada pada jaringan tidak memenuhi syarat. 


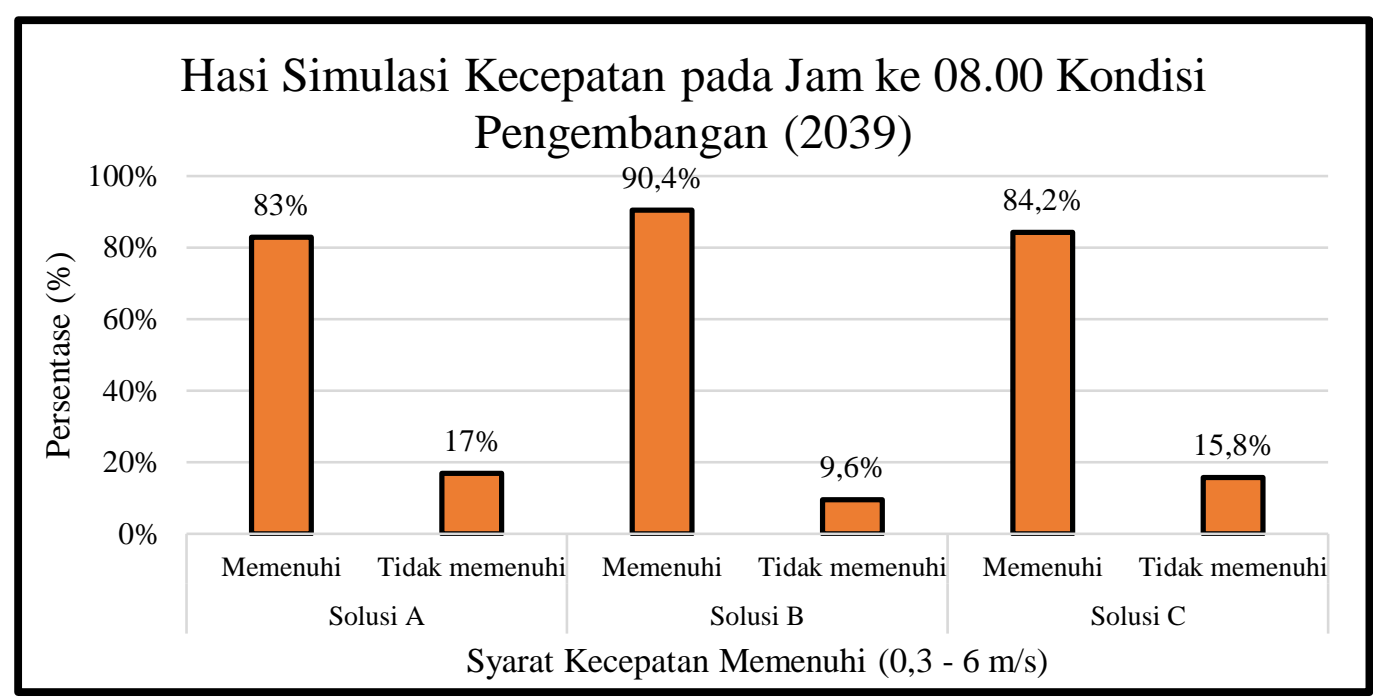

Gambar 7: Hasil Simulasi Kecepatan pada Jam ke 08.00 Kondisi Pengembangan (2039)

Dari gambar diatas menunjukan pada simulasi kecepatan solusi B memiliki persen memenuhi syarat yang paling tinggi dengan $90,4 \%$. Pada simulasi kecepatan masig-masing solusi memiliki persen memenuhi syarat diatas $80 \%$. Adapun syarat memenuhi kecepatan adalah $0,3-6 \mathrm{~m} / \mathrm{s}$.

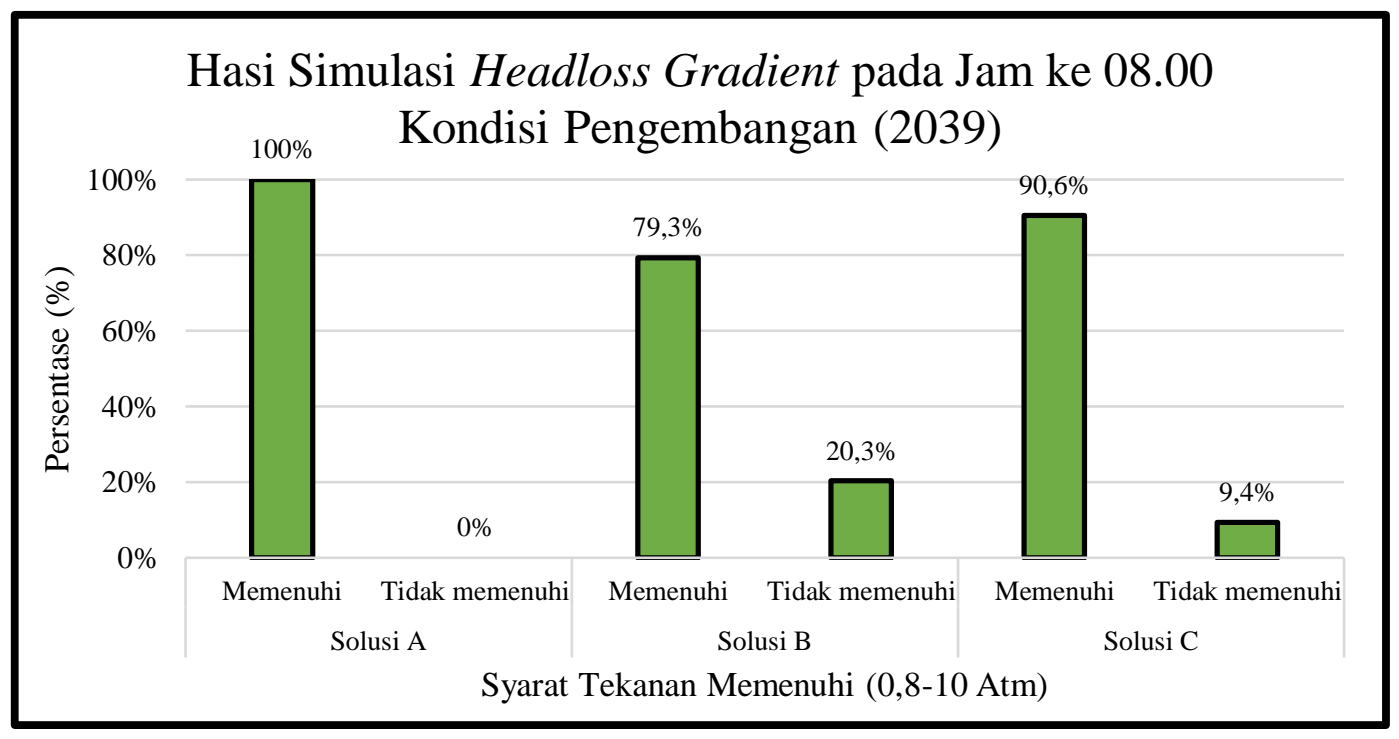

\section{Gambar 8: Hasil Simulasi Headloss Gradient pada Jam ke 08.00 Kondisi Pengembangan (2039)}

Dari gambar diatas menunjukan pada simulasi headloss gradient solusi A memiliki persen memenuhi syarat yang paling tinggi dengan $100 \%$. Solusi B memiliki persen memenuhi terkecil dengan $79,3 \%$. Adapun syarat memenuhi headloss gradient adalah $0-15 \mathrm{~m} / \mathrm{km}$.

Pada kondisi pengembangan penginjeksian klorin di tandon krembangan ditambahkan 0,2 mg/l menjadi $1,4 \mathrm{mg} / \mathrm{l}$. Pada simulasi ini juga ditentukan konsentrasi klorin pada tandon sebelum penginjeksian sebesar $1 \mathrm{mg} / \mathrm{l}$. Hasil simulasi sisa klorin menggunakan aplikasi WaterCad v8i hasilnya $100 \%$ memenuhi syarat yang diizinkan. Adapun syarat memenuhi sisa klorin adalah $0,2-0,5 \mathrm{mg} / \mathrm{l}$. Pada simulasi ini ditinjau sisa klorin pada junction mulai dari $\mathbf{J}-1$ hinggal junction yang berada di hilir jaringan $\mathbf{J}-121$. Hasil simulasi tersebut menjelaskan bahwa sisa klorin pada seluruh jaringan sudah memenuhi syarat. 


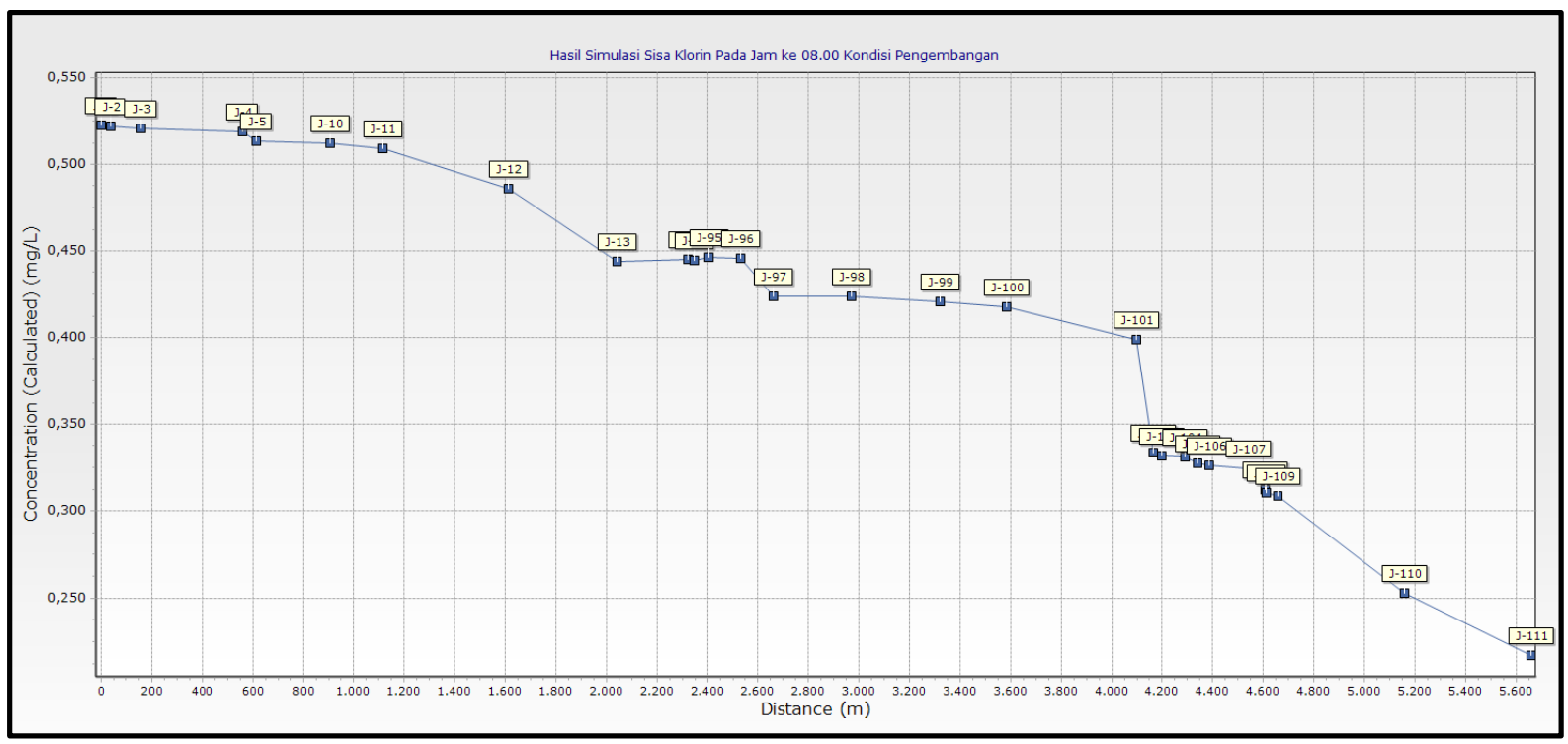

Gambar 9: Hasil Simulasi Sisa Klorin pada Jam ke 08.00 Kondisi Pengembangan (2039)

Dari gambar diatas, dapat dilihat sisa klorin semakin jauh jarak maka semakin turun sisa klorinnya. Pada junction 1, terdapat sisa klorin sebesar $0,52 \mathrm{mg} / \mathrm{L}$, sedangkan pada junction 111 sisa klorin sebesar $0,22 \mathrm{mg} / \mathrm{L}$. jarak dari $\mathbf{J}-1 \mathrm{ke} \mathbf{J}-111$ sendiri adalah $5,5 \mathrm{~km}$. selain panjang jaringan, pipa yang bercabang juga berpengaruh terhadap sisa klorin. Pipa yang lurus tanpa bercabang akan menghasilkan sisa klorin yang cenderung stagnan, sedangkan jaringan pipa yang panjang dan bercabang akan menghasilkan sisa klorin dengan penurunan drastis.

\subsection{Sumur Pemadam Kebakaran (SPMK)}

Sumur Pemadam Kebakarang pada jaringan distribusi air bersih memilki peran sebagai pengganti hidran. Air dalam sumur bersumber pada jaringan pipa PDAM terdekat dengan sumur tersebut. Sumur PMK pada kondisi eksisting memiliki kapasitas sebesar $5 \mathrm{~m}^{3}$. Kondisi di lapangan, air yang masuk ke dalam sumur masih menggunakan cara manual untuk mengisinya. Namun pada simulasi ini digunakan TCV untuk mengatur aliran yang masuk ke dalam sumur. Berikut gambar permodelan sumur PMK pada WaterCad V8i.

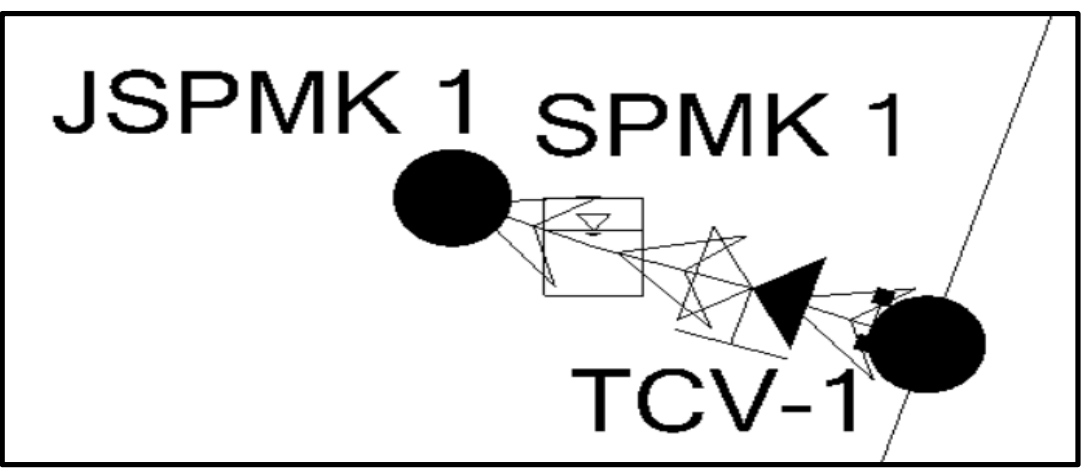

Gambar 10: Permodelan SPMK pada program WaterCad v8i (2039)

Untuk kondisi ideal, sumur pemadam kebakaran harus ada dalam radius $500 \mathrm{~m}$. Seiring dengan berkembangnya teknologi, kapasitas mobil PMK yang baru menjadi $10 \mathrm{~m}^{3}$ yang mengharuskan sumur PMK pun memuliki kapasitas yang sama agar mempercepat dalam pengisian penuh mobil PMK. Sehingga pada pengembangan, SPMK menjadi memiliki kapasitas $10 \mathrm{~m}^{3}$. 
Tabel 5: Sebaran Sumur Pemadam Kebakaran

\begin{tabular}{ccccc}
\hline No & No SPMK & SubZona & Kapasitas $\left(\mathrm{m}^{3}\right)$ & Status \\
\hline 1 & SPMK - 1 & 309 & 5 & Eksisting \\
2 & SPMK - 2 & 309 & 5 & Eksisting \\
3 & SPMK - 3 & 313 & 5 & Eksisting \\
4 & SPMK - 4 & $309 / 313$ & 5 & Eksisting \\
5 & SPMK - 5 & 314 & 5 & Eksisting \\
6 & SPMK - 6 & 314 & 5 & Eksisting \\
7 & SPMK - 7 & 316 & 5 & Eksisting \\
8 & SPMK - 8 & 313 & 10 & Pengembangan \\
9 & SPMK - 9 & 315 & 10 & Pengembangan \\
\hline
\end{tabular}

Pada penelitian ini dilakukan simulasi terjadinya kebakaran untuk mengetahui kemampuan jaringan dalam mengisi sumur pemadam kebakaran. Simulasi kebakaran dilakukan sebanyak lima kali dalam sehari dengan asumsi semua sumur digunakan untuk membantu memadamkan kebakaran. Kebakaran terjadi pada jam ke 00.00, 08.00, 12.00, 16.00, dan 24.00. Jam tersebut diambil berdasarkan pertimbangan jam pemakaian sedang, minimal, dan maksimal. Berikut hasil simulasi sumur pemadam kebakaran kondisi eksisting (2019). Berikut hasil Simulasi pada SPMK 9.

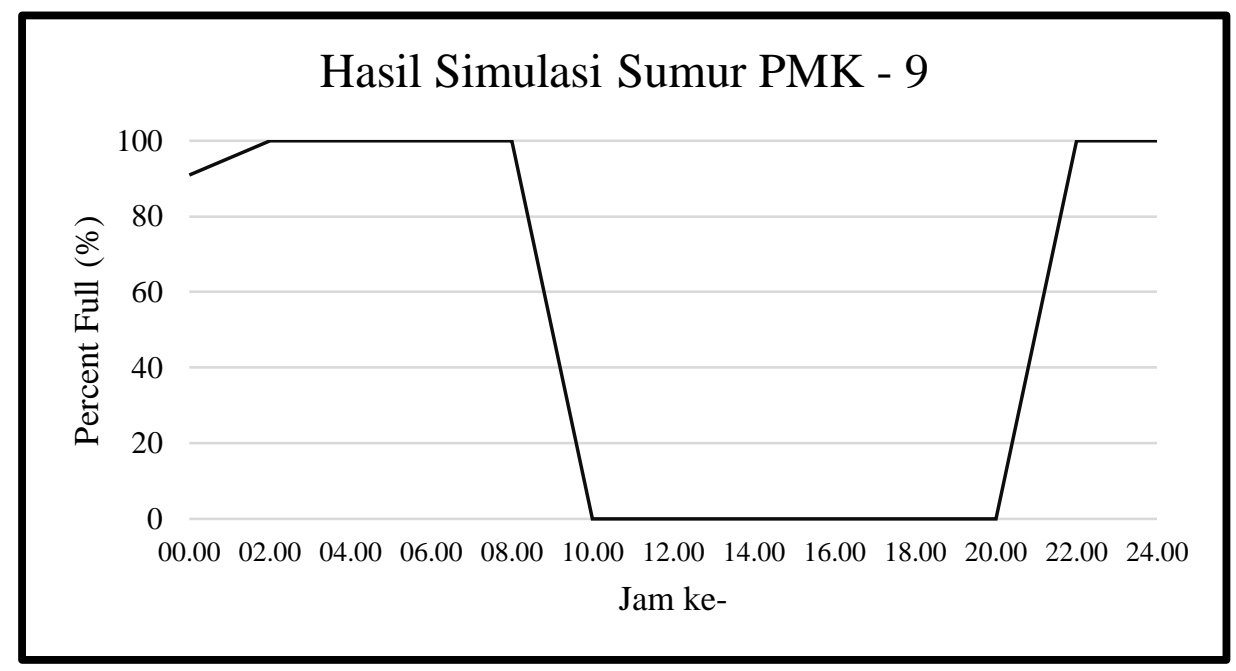

Gambar 11: Hasil Simulasi SPMK 9 (2039)

Hasil simulasi diatas menunjukan bahwa pada pukul 10.00 sampai pukul 20.00 SPMK masih belum dapat terisi penuh kembali dikarenakan pemakaian air yang masih tinggi pada jaringan.

\section{Kesimpulam}

Ketersediaan air pada RP Krembangan adalah sebesar 220 liter/detik. Pada kondisi eksisting (2019) kebutuhan air sebesar 369 liter/detik dapat disimpulkan ketersediaan air kurang. Pada kondisi pengembangan (2039) dengan pertambahan pelanggan, maka diberikan tiga solusi untuk mengurangi defisit kekurangan air. Solusi tersebut adalah mengurangi standar kebutuhan air menjadi 80 liter/orang/hari (299,7 liter/detik), melakukan penggiliran pengaliran air sesuai kluster (309,1 liter/detik), dan pengurangan daerah pelayanan (262,2 liter/detik). Ketiga solusi tersebut selanjutnya ditinjau pada simulasi hidraulik dan kualitas air untuk diketahui mana yang paling baik.

Simulasi pada kondisi eksisting (2019) menunjukan bahwa nilai tekanan, kecepatan, dan headloss gradient masih belum memenuhi syarat. Untuk menunjang kondisi pengembangan (2039) maka dilakukan penambahan pipa yang dipasang secara paralel dan penambahan pompa. Hasilnya pada kondisi pengembangan jaringan simulasi menunjukan hasil yang lebih baik. Untuk solusi terbaik jika dilihat dari kebutuhan air dan aspek hidraulika adalah solusi C. Pada Kondisi eksisting simulasi kualitas 
air belum mencapai target sisa klorin, lalu pada kondisi pengembangan ditambahkan injeksi sebesar 0,2 $\mathrm{mg} / \mathrm{l}$ dan hasil simulasi menunjukan pada ujung jaringan sisa klorin terpenuhi.

Sumur pemadam kebakaran dilakukan simulasi dengan tedapat penambahan dua SPMK yang memiliki kaspasitas $10 \mathrm{~m}^{3}$. Simulasi dilakukan pada sembilan SPMK yang hasilnya menunjukan semakin jau titik SPMK dari sumber makan semakin lama terisi penuh kembali. Pada jam pemakaian pada rata-rata SPMK setelah pada jam 08.00 habis terpakai, bari bisa terisi kembali pada pukul 16.00.

\section{Daftar Pustaka}

[1] J.S. Fidari, R.D. Lufira, E. Purwati, R. Haribowo., "Evaluation and Development of Network Distribution of Clean Water PDAM Unit Lawang", The 7th Annual Basic Science International Conference (BaSIC 2017) 1, 194

[2] Bentley Methods. 2007. User's Guide WaterCAD v8i for Windows WATERBUY CT. USA: Bentley Press.

[3] E.W. Diana, M. Solichin, R. Haribowo., "A study of clean water distribution network development at PDAM Tirta Barito in the city of Buntok", IOP Conference Series: Earth and Environmental Science 437 (1), 012002

[4] Badan Pusat Statistik. 2015. Pedoman Perhitungan Proyeksi Penduduk dan Angkatan Kerja. Jakarta: Badan Pusar Statistik.

[5] Dayan, Anton. 1980. Pengantar Metode Statistik Jilid Satu. Jakarta: LP3ES.

[6] Priyantoro, Dwi. 1991. Hidraulika Saluran Tertutup. Malang: Jurusan Pengairan Fakultas Teknik Universitas Brawijaya.

[7] Effendi, H., Telaah Kualitas Air, Bagi Pengelolaan Sumberdaya dan Lingkungan Perairan. Yogyakarta: Kanisius, 2003.

[8] Triatmadja, Radianta. 2013. Hidraulika Sistem Jaringan Perpipaan Air Minum. Yogyakarta: Beta Offset..

[9] Triatmadja, Radianta. 2014. Teknik Penyediaan Air Minum Perpipaan. Yogyakarta: Beta Offset.

[10] Keputusan Menteri Kesehatan Republik Indonesia. Nomor 416/Menkes/PER/IX/1990/1990. Syarat - Syarat dan Pengawasan Kualitas Air Bersih.

[11] Kementrian Pekerjaan Umum. 2007. Penyelenggaraan Pengembangan Sistem Penyediaan Air Minum. Jakarta: Kementrian Pekerjaan Umum.

[12] E. Rohmaningsig, M. Solichin, R. Haribowo., "Kajian Pengembangan Sistem Penyediaan Air Bersih Pada Daerah Rawan Air Di Desa Sumbersih Kecamatan Panggungrejo Kabupaten Blitar", Jurnal Teknik Pengairan 8 (1), 48-59 